\title{
Initiating curriculum mapping on the web-based, interactive learning opportunities, objectives and outcome platform (LOOOP)
}

\author{
I Treadwell, ${ }^{1}$ MCur, DCur; O Ahlers, ${ }^{2} \mathrm{MD}, \mathrm{PhD} ; \mathrm{G}$ C Botha, ${ }^{3} \mathrm{MA}$, MPhil HSE \\ ${ }^{1}$ LOOOP Project manager, Sefako Makgatho Health Sciences University, Pretoria, South Africa \\ ${ }^{2}$ LOOOP Project, Department of Anaesthesiology, Charité - Universitätsmedizin Berlin, Germany \\ ${ }^{3}$ Practice of Medicine, Sefako Makgatho Health Sciences University, Pretoria, South Africa
}

Corresponding author: I Treadwell (ina.treadwell@gmail.com)

\begin{abstract}
Background. A web-based curriculum is made transparent by providing multidimensional overviews of content (learning objectives) aligned with learning outcomes and frameworks, opportunities and assessment formats. A South African university embarked on the mapping of its curricula on the web-based learning opportunities, objectives and outcome platform (LOOOP).

Objectives. To reflect on the customisation of LOOOP and training of lecturers, and to determine lecturers' perceptions of the usability and value of LOOOP. Methods. The project manager reflected on the initiating processes, and a survey determined the lecturers' perceptions of the usability and value of curriculum mapping, using a 4-point Likert scale questionnaire. The convenience sample comprised the first 30 lecturers who had uploaded their curriculum content and consented to partake in this ethics-approved study. Descriptive statistics portray the percentages of agreement on the positive statements of the questionnaire.

Results. Challenges related to slow staff buy-in and development were experienced. Required modifications to LOOOP were promptly dealt with. The majority of participants agreed on the usability $(\geq 89 \%)$, as well as structure and transparency $(\geq 87 \%)$ of LOOOP. Mapping is expected to enhance curriculum revision $(\geq 95 \%)$ and communication ( $\geq 96 \%)$, viewing the curriculum scope, complexity and cohesion (97\%), as well as abstracting data for management analysis and reporting (100\%).

Conclusions. The lecturers agreed on the usability and values of curriculum mapping, which indicates that online mapping is sufficiently beneficial to justify the time and resources invested. Mapping should be a product of collaborative participation and planned as a long-term commitment, which can also be used to research the impact of mapping on student learning.
\end{abstract}

Afr J Health Professions Educ 2019;11(1):27-31. DOI:10.7196/AJHPE.2019.v11i1.1073

A challenge in curriculum designing and refining is to ensure that objectives for knowledge, skills and attitudes are clear, structured within the learning opportunities of modules, and aligned with assessment formats, outcomes, competencies and content taxonomies. Curriculum mapping entails a process of matching learning outcomes with elements of the curriculum ${ }^{[1]}$ and provides the required visual representation of these various curriculum components, attributes and relationships. ${ }^{[2]}$ The challenge of alignment can therefore be met by mapping on an electronic platform, which provides for the systematic organisation and linking of various curriculum elements into a database..$^{[3-5]}$ Harden $^{[3]}$ describes curriculum mapping as a blueprint that provides a multidimensional overview of four interrelated key areas: content (learning objectives), learning outcomes, learning opportunities (events contributing to outcomes) and the related assessment. Viewing the map through these four 'windows' reveals what has to be learnt, how it can be learnt and how it must be assessed. Curriculum mapping visually represents key elements of a programme that contributes to student learning. ${ }^{[1]}$

A relational curriculum database as described above makes the curriculum transparent owing to the online accessibility and search ability. It allows users to browse through the information in different ways ${ }^{[6]}$ to view aligned content by using descriptors in various hierarchies of the outcomes, competencies and content taxonomies as keywords to filter data. The power of the map clearly lies in the links between curriculum elements ${ }^{[7]}$ on which these searches are based. The transparency of the curriculum map enables the visibility of students' prior exposure to particular content and planning of the level and breadth of new learning. ${ }^{[3]}$ Viewing the learning spiral by filtering the progression in terms of breadth, depth, utility and proficiency, as reflected in learning objectives, ${ }^{[4]}$ clarifies students' and educators' understanding of where students are going and the steps they need to take to get there. ${ }^{[4,8]}$

Revision of a curriculum is facilitated through multiple searching and reporting features of a curriculum map. Educators are enabled to check for redundancies, inconsistencies, misalignments and weaknesses. ${ }^{[9]}$ This includes reviewing whether the content is congruent with expected learning outcomes, ${ }^{[3,5,6]}$ considering the availability of teachers and suitable patients, ${ }^{[5]}$ identifying learning objectives that are not covered or overlap with other content domains and detecting inconsistencies between objectives and assessment. ${ }^{[10]}$ The map provides for a review of assessment methods, ${ }^{[9]}$ and by correcting inconsistencies and possible mismatches between teaching and assessment, valid examinations can be constructed. ${ }^{[3]}$ Viewing the scope of these patterns and relationships, complexity and cohesion of the curriculum $^{[11]}$ are important for the purposes of curriculum management, analysis and reporting. ${ }^{[7,12,13]}$

A web-based curriculum platform facilitates constant evaluation, updating and improving of curricula in real time, driving improvements to learning and teaching practices, ${ }^{[14]}$ and is seen as an essential tool to 
operationalise and review a curriculum. ${ }^{[5,6]}$ According to Harden, ${ }^{[3]}$ 'No good curriculum can afford to be without one'. The use of a multidimensional curriculum map has therefore become increasingly necessary to model, track and report on curricula. ${ }^{[13]}$

A South African (SA) university embarked on a project to map their curricula online. A web-based platform for curriculum mapping, known as the learning opportunities, objectives and outcome platform (LOOOP), as described by Balzer et al., ${ }^{[5]}$ was acquired by joining the non-commercial, international LOOOP network. LOOOP was designed by a team of academics and information technology programmers from Charité Universitätsmedizin Berlin, Germany, who have been using, updating and researching the system and its concepts since 2004.

\section{Objectives}

The aim of this article is to report:

- reflections of the project manager on the process of adapting LOOOP and initiating lecturers' mapping of curriculum content

- lecturers' perceptions of the usability of LOOOP, as well as the experienced and expected values of curriculum mapping.

\section{Methods}

A mixed methods design was used in this study. The project manager reflected on the adaptations made to customise LOOOP and on the training of lecturers during the initial period of mapping the curriculum content.

The research design to determine lecturers' perspectives was explorative and descriptive, with a quantitative approach embedded in a survey as methodology.

The population comprised lecturers $(n=175)$ who had received training and assistance between October 2015 and May 2016. Lecturer training was done throughout by the same person (the project manager) to enhance consistency and reduce bias. After the training, these lecturers had to complete the mapping on their own. The convenience sample comprised the first 30 lecturers who had completed uploading of their curriculum content by May 2016 and consented to partake in this ethics-approved study.

A tested, self-constructed 4-point Likert scale questionnaire was used to determine the participants' perceptions of the use of and experienced and expected values of curriculum mapping. The content validity of the questionnaire was assured by basing the questions on the literature and having the three researchers validate the appropriateness of the items. Qualitative data were obtained from the comment section in the questionnaire.

Descriptive statistics were used to portray the percentage of agreement on the positive statements of the questionnaire. 'Agree' in the text refers to the combination of 'Agree' and 'Strongly agree' in the graphs, unless otherwise indicated.

\section{Results}

\section{Reflections on adapting LOOOP and initiating lecturers' uploading of curriculum content}

Our institution acquired LOOOP in 2015. A full-time academic with qualifications in healthcare sciences and education volunteered to be contracted as project manager. She was trained and supported in the use of LOOOP by the Charité team (project manager as well as programmers).

Initially, the process of mapping had a bottom-up approach, and a lack of managerial impetus was experienced. Management supported the LOOOP project financially, but did not become involved.

\section{Adaptation}

LOOOP was adapted to address the needs of the institution and the requests throughout this process were promptly dealt with by support from the LOOOP team at Charité. The following outcome and competency frameworks have been added:

- Core competencies in the seven roles of medical and dental practitioners, as adapted from CanMEDS by the Health Professions Council of SA. ${ }^{[15]}$

- The Medical Subject Headings (MeSH) index catalogue, ${ }^{[16]}$ with subject headings as descriptors, is used as a catalogue of core diseases. MeSH provides hierarchically organised terminology for the indexing of biomedical information, ranging from very broad headings to more specific terms. The 13-level hierarchy was condensed to 3 levels, ${ }^{[7]}$ which include descriptors of the core diseases identified at the institution.

- Level descriptors for the SA National Qualifications Framework. ${ }^{[17]}$

- Exit-level outcomes for the various courses offered at the institution.

\section{Initiating the uploading of curriculum content}

Demonstrations of the functionalities of LOOOP were given to academic departments and to relevant committees, and lecturers were invited to upload their curriculum elements. The process of populating LOOOP started in 2015 by uploading modules in the undergraduate medical programme. Module outcomes and assessment formats were added during the uploading phase. The project manager trained the lecturers individually and in small groups. Mapping of educational objectives to domains, levels in taxonomies and active verbs was facilitated by online support of LOOOP. Objectives copied from existing study guides were reviewed during the process and often changed to improve on construction or the required level of a domain taxonomy. Contextual relationships were then created by aligning these objectives with outcomes, competencies and frameworks, as listed above, as well as assessment formats.

Being a volunteer as well as a full-time academic resulted in slow progress in the population of LOOOP. The manager's limited time to train lecturers was exacerbated by slow staff buy-in, participation and development. The uploading of objectives was done from existing study guides, but for some of the modules the objectives had to be formulated and the level of domain had to be explained, which proved to be time-consuming. The attitude of reluctance observed among lecturers in many cases changed to enthusiasm when they realised the value of a curriculum map, as reflected in their comments reported in the questionnaire.

\section{Lecturers' perceptions of the usability and value of curriculum mapping}

Fig. 1 reflects lecturers' perceptions of the usability and ease of curriculum mapping in general and the linking of objectives to domains, outcomes, frameworks and assessment formats.

There was $\geq 89 \%$ agreement of participants on the usability statements. Almost all participants agreed on the ease of linking of objectives, with the exception of $20 \%$, who found the linking to $\mathrm{MeSH}$ problematic. No respondent disagreed strongly with the statements.

The agreement on positive value statements of LOOOP as experienced by respondents is reported in Fig. 2.

Almost all respondents valued LOOOP in general, the structure and alignment of curriculum elements in particular, and the search ability very highly. 


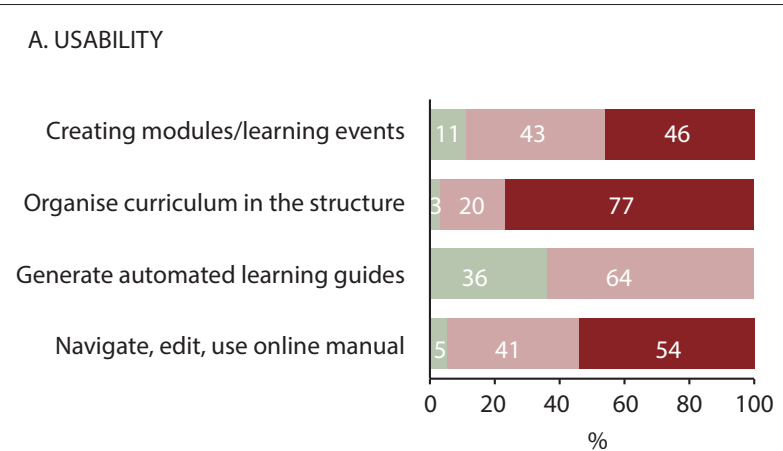

B. EASE OF LINKING OBJECTIVES TO CURRICULUM ELEMENTS

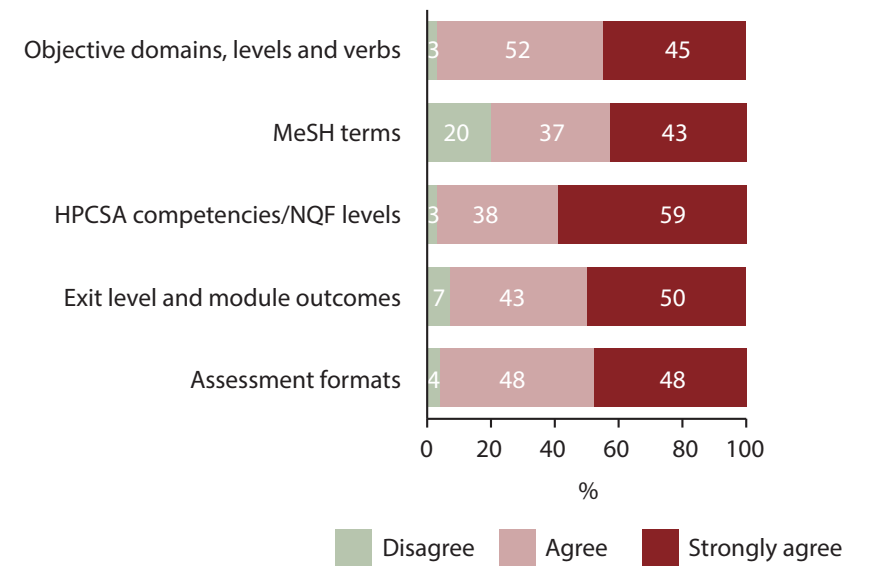

Fig. 1. Perceptions of curriculum mapping $(\mathrm{n}=30)$. $($ MeSH $=$ Medical Subject Headings; HPCSA = Health Professions Council of South Africa; NQF = National Qualifications Framework.)

Lecturers' expected values of LOOOP once all the modules of a curriculum had been populated are reflected in Fig. 3.

Respondents $(\geq 97 \%)$ had very high expectations of LOOOP being transparent and familiar, and facilitating an integrated approach once the uploading of all curriculum content had been completed. The visibility of students' prior learning was expected to be useful in planning the level and breadth of new learning, sequencing, and monitoring vertical and horizontal integration (96\%). Respondents indicated that revision of the curriculum should also be enhanced $(\geq 95 \%)$.

Communicating curriculum and assessment matters to students was expected to be very valuable ( $\geq 96 \%)$. The majority of respondents agreed that the visibility of the curriculum scope, complexity and cohesion (97\%), as well as abstracting of data (100\%), are very beneficial for management analysis and reporting purposes. No respondent disagreed strongly with the statements.

The respondents commented positively on the mapping of their curriculum content on LOOOP:

'This process forced me to re-evaluate my study guide, which was necessary'.

'It [the guide] is easily updateable.'

'... happy to have an electronic, transparent guide for easy use by lecturer and student.'
'It saves the cost of printing the curriculum guide every year.'

'I love the fact that I can now see what my students will learn in other subjects. This helps me to focus more on the important areas of my course.'

'A good tool which I think will benefit the students and lecturers to have a good idea how learning topics fit in the whole curriculum.'

'LOOOP helped me to re-evaluate and restructure my course content in a more holistic and systematic way'.

'Excellent tool to prepare for accreditation visits.'

'Opening up exciting possibilities to get data easier for the purpose of educational research.'

\section{Discussion}

\section{Adaptation of LOOOP and initiating the uploading of curriculum content}

All modifications to LOOOP were made promptly to address the needs at the institution. This is important, as studies on curriculum mapping inform that mapping is an ongoing process that requires continual upgrading and maintenance. ${ }^{[6,14]}$ According to Hale, ${ }^{[18]}$ a map should never be considered complete and done with.

The lack of dedicated time and personnel for curriculum mapping at our institution concurs with the literature, which states that the greatest concerns regarding the construction and maintenance of electronic platforms for curriculum mapping focus on the demand for time and human resources. ${ }^{[5,6,13,19]}$ Slow staff buy-in, participation and development were experienced, which are similar to the findings of Watson $e^{\text {al }}{ }^{\left[{ }^{[14]}\right.}$ and Willet ${ }^{[6]}$ Studies indicate that working with busy academic staff to review a curriculum is complex, time-consuming and often unpredictable. ${ }^{[20]}$ Reluctance in some cases, especially of clinical staff, could possibly be ascribed not only to busy schedules, and understandably priority of patient care, but also to lack of an education background or understanding. Lecturers are challenged to map the contextual relationships in the curriculum for which they are responsible. ${ }^{[7]} \mathrm{Hale}^{[18]}$ also reported moments of frustration, that some lecturers learn faster than others and that some need more support, while others may refuse to participate actively. However, the uploading of objectives from existing study guides often resulted in revision thereof, which could be seen as a quality assurance process.

A lack of managerial impetus was probably due to student unrest and the transition to a new university that took precedence. Hale ${ }^{[18]}$ emphasises that curriculum mapping is not a 'spectator sport'; there must be continual support from administrators, where educators have to learn or expand their understanding of curriculum design. Appropriate leadership and ongoing educational support are needed to overcome inertia among educators when matters of curricula are raised, which is common in universities. ${ }^{[12]}$ The need for transformational leadership must be emphasised, as it embraces teaching, coaching, mentoring, facilitating, inspiring, influencing and bringing about effective change. ${ }^{[21]}$

\section{Usability of curriculum mapping and experienced and expected values}

The ease of linking to and navigating in LOOOP is promising, as the usability of the interface, according to Willet, ${ }^{[6]}$ has been proven to have a great impact on the use and success of the electronic system. It therefore has to be user-friendly and non-threatening. ${ }^{[3]}$ 


\section{Research}

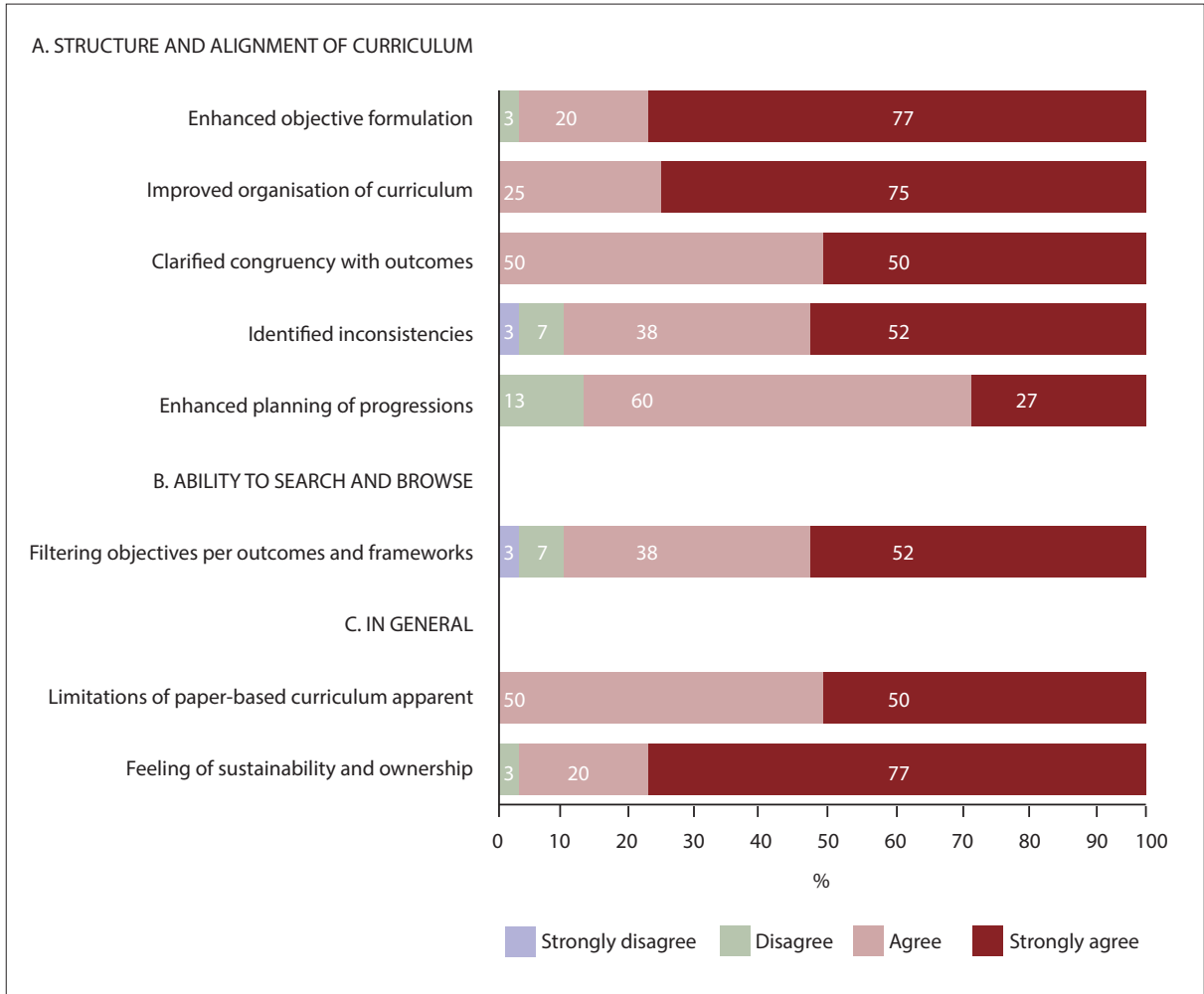

Fig. 2. Perceptions of the value of $L O O O P$, as experienced $(n=30)$. ( $L O O O P=$ learning opportunities, objectives and outcome platform.)

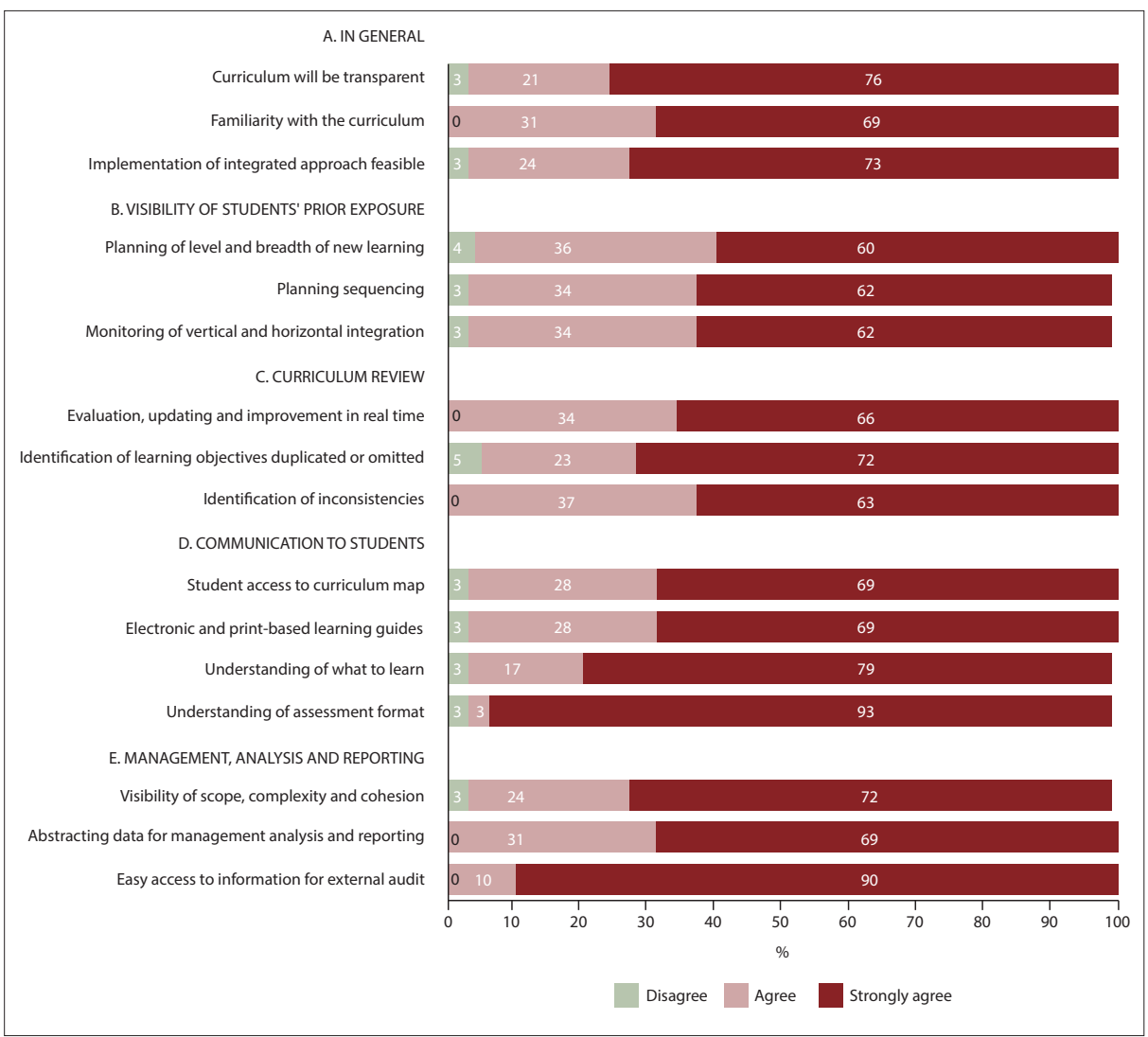

Fig. 3. Perceptions of the value of LOOOP, as expected $(\mathrm{n}=30)$. (LOOOP = learning opportunities, objectives and outcome platform.)
The linking of objectives to the MeSH framework, however, was the exception. This could probably be due to unfamiliarity with the framework and in some cases the absence of suitable subcategories. The LOOOP team, who added a few subcategory terms to $\mathrm{MeSH}$, have addressed this issue.

The structure, alignment and filtering of curriculum elements were highly valued, which is encouraging, as it is claimed that mapping facilitates the staff and students' understanding of planned progression and complex relationships between learning outcomes, opportunities and content. Mapping provides for transparency, ${ }^{[4]}$ and by identifying students' prior learning, educators can focus on building on previous knowledge. ${ }^{[9]}$ The feeling of sustainability and sense of ownership reported by almost all the respondents are promising, as this would result in academic and clinical teaching staff who are involved. ${ }^{[14]}$ The use of LOOOP made the respondents aware of the limitations of a paperbased curriculum, which concurs with Harden's ${ }^{[3]}$ statement that it is impossible to reproduce the different elements of a curriculum and the interrelationships between these elements on a paper version of a map.

The respondents' expectations of a transparant and familiar curriculum should be beneficial for implementing an integrated approach, ${ }^{[3]}$ as well as for integration among disciplines. ${ }^{\left[{ }^{[3]}\right.}$ The visibility of students' prior learning, as expected through mapping, should facilitate the planning of the level and breadth of new learning, ${ }^{[3]}$ as well as monitoring of vertical and horizontal integration, planning the sequencing of content and avoidance of duplication. ${ }^{[14]}$

The value of mapping for revision purposes became very clear and concurs with Hale, ${ }^{[22]}$ who emphasised the importance of taking adequate time to review a map for multiple purposes to gain insights into gaps, absences and redundancies in a curriculum.

The communication functionalities as expected correspond to claims in the literature. Hale ${ }^{[18}$ describes a mapping system as a $24 / 7$ communication tool that provides educators and administrators with evidence of the planned and taught curriculum, horizontally and vertically. It also provides educators and students with a shared understanding of what the curriculum seeks to accomplish, i.e. a view of the bigger picture. ${ }^{[23]}$ Students can view clear statements of the learning outcomes at each stage, and how these match with learning outcomes, 
learning experiences and assessments in an electronic or print-based study guide. ${ }^{[24]}$

Due to easy access to required curricular information, the respondents had very high expectations of LOOOP in terms of management, analysis, reporting and accreditation processes. Showing relationships between the elements provides a visual analytical tool and makes evident the need for strategy decisions, which in turn can lead to improvements. ${ }^{[3]}$ The use of curriculum mapping as preparation for accreditation has been described by Perlin ${ }^{[25]}$ as a transformational experience in curriculum quality for faculty.

The comments of participants on the usability and values of LOOOP were extremely positive. Not only did they experience the structuring and alignment of curriculum elements and the search ability as very valuable, but also the expected transparency and communication functionalities needed for familiarity with the curriculum that will enable integration review, informed management and reporting.

\section{Conclusion and recommendations}

In light of the high level of agreement of lecturers on the usability and values that they experienced with and expected of curriculum mapping, it can be concluded, in concurrence with Willet, ${ }^{[6]}$ to be sufficiently beneficial to justify the time and resources invested. The value of mapping in terms of alignment of curriculum elements, transparency, filtering of objectives, communication, management and reporting has been thoroughly acknowledged.

Except for the appointment of a project manager with a healthcare and educational background, lecturers from key areas in a faculty need to be identified and allowed protected time to function as members of a leadership team. It is recommended that such a team should consist of a member from top management, the project manager and committed lecturers representing departments, or schools should be formed to drive a curriculum mapping initiative and to research the impact of mapping on student learning. Mapping should be a product of collaborative participation in an organisation's ongoing curriculum, as education is not a static environment. It is designed to become a component of an educational system's infrastructure ${ }^{[18]}$ and should be planned as a longterm commitment, ensuring that the map is sustained and used in ways expected by lecturers, who spent time and effort to revise and upload their curricula.

Declaration. None.

Acknowledgements. None.
Author contributions. IT: conceptualisation, design, analysis and interpretation of data, drafting of important scientific content and approval of the version to be published; OA: design, analysis and interpretation of data, critical revision of important scientific content and approval of the version to be published; GCB: design, analysis and interpretation of data, critical revision of important scientific content and approval of the version to be published.

Funding. None.

Conflicts of interest. None.

1. Pierce G. Curriculum mapping. 2015. https://www.bu.edu/provost/files/2015/04/4.8.15-CEIT-Teaching-TalkAssessment-Curriculum-Mapping-PowerPoint.pdf (accessed 13 November 2018).

2. Komenda L, Karolyi M, Vaitsis C, Spachos D, Woodham, L. A pilot medical curriculum analysis and visualization according to medbiquitous standards. 30th EEE International Symposium on Computer-Based Medical System - IEEE CBMS 2017, Thessaloniki, Greece, 22 - 24 June 2017. http://cbms2017.org/slot/pilot-medical-curriculumanalysis-and-visualization-according-medbiquitous-standards (accessed 12 November 2018).

3. Harden RM. AMEE Guide No. 21. Curriculum mapping: A tool for transparent and authentic teaching an learning. Med Teach 2001;23(2):123-137. https://doi.org/10.1080/01421590120036547

4. Harden RM. Learning outcomes as a tool to assess progression. Med Teach 2007;29(7):678-682. https://doi org/10.1080/01421590701729955

5. Balzer F, Hautz WE, Spier C, et al. Development and alignment of undergraduate medical curricula in a web-based, dynamic learning opportunities, objectives and outcome platform (LOOOP). Med Teach 2016;38(4):369-377. https://doi.org/10.3109/0142159X.2015.1035054

6. Willet T. Current status of curriculum mapping in Canada and the UK. Med Educ 2008;42(8):786-793. https//doi org/10.1111/j.1365-2923.2008.03093.x

7. Blaum WE, Jarczewski A, Balzer F, Stotzner F, Ahlers O. Towards Web 3.0: Taxonomies and ontologies for medical education - a systematic review. GMS Z Med Ausbild 2013;30(1):13. https://doi.org/10.3205/zma000856

8. Prideaux D. Curriculum development in medical education: From acronyms to dynamism. Teach Teach Educ 2007;23:294-302.

Education World. Virtual workshop: Curriculum mapping. 2016. http://www.educationworld.com/a_curr/ virtualwkshp/curriculum_mapping.shtml (accessed 12 November 2018).

. Hege I, Nowak D, Kolb S, Fischer MR, Radon K. Developing and analysing a curriculum map in occupational and environmental medicine. BMC Med Educ 2010;10:60. https://doi.org/10.1186/1472-6920-10-60

1. Prideaux D. ABC of learning and teaching in medicine: Curriculum design. BMJ 2003;326:268-270

12. Britton M, Letassy N, Medina MS, Nelson ER. A curriculum review and mapping process supported by an electronic database system. Am J Pharm Educ 2008;72(5):99.

3. Ellaway RH, Albright S, Smothers V, Cameron T, Willet T. Curriculum inventory: Modelling, sharing and comparing medical education programs. Med Teach 2014;36(3):208-215

14. Watson EGS, Moloney PJ, Toohey SM, et al. Development of eMed: A comprehensive, modular curriculummanagement system. Acad Med 2007;82(4):351-360.

15. Health Professions Council of South Africa. Core competencies for undergraduate students in clinical associate dentistry and medical teaching and learning programmes in South Africa. 2014. http://www.hpcsa.co.za/uploads/ editor/UserFiles/downloads/medical_dental/MDB\%20Core\%20Competencies\%20-\%20ENGLISH $\% 20-\% 20$ FINAL\%202014.pdf (accessed 12 November 2018).

16. US National Library of Medicine. Medical subject headings. 2017. https://www.nlm.nih.gov/mesh/ (accessed 17 July 2017).

17. South African Qualifications Authority (SAQA). Level descriptors for the South African National Qualification Framework. 2012. http://www.saqa.org.za/docs/misc/2012/level_descriptors.pdf (accessed 19 June 2017).

18. Hale JA. A Guide to Curriculum Mapping: Planning, Implementing, and Sustaining the Process. Thousand Oaks, CA: Corwin Press, 2008.

9. Davis MH, Harden RM. Planning and implementing an undergraduate medical curriculum: The lessons learnt. Med Teach 2003;25(6):596-608. https://doi.org/10.1080/0142159032000144383

20. Oliver B, Jones S, Ferns S, Tucker, B. Mapping curricula: Ensuring work-ready graduates by mapping course learning outcomes and higher order thinking skills. ANT Evaluation and Assessment Conference, Brisbane, Australia, 29 30 November 2007. http://c2010.curtin.edu.au/local/docs/paper3.pdf (accessed 12 November 2018).

21. Hale JA, Dunlap RF. An educational leader's guide to curriculum mapping: Creating and sustaining collaborative cultures. 2010. https://us.corwin.com/en-us/nam/book/educational-leaders-guide-curriculum-mapping (accessed 17 July 2017).

22. Hale JA. Curriculum decisions. Curriculum mapping basics. http://curriculumdecisions.com/curriculum-mappin (accessed 12 November 2018).

23. Carney E. Curriculum mapping: A quick guide for programs. 2015. https://atl.wsu.edu/documents/2015/03 curriculum-mapping.pdf (accessed 15 July 2017).

24. Dent JA, Harden R. A Practical Guide for Medical Teachers. 4th ed. London: Churchill Livingston, 2013

25. Perlin MS. Curriculum mapping for program evaluation and CAHME accreditation. I Health Admin Educ 2011;28(1):33-53.

Accepted 17 July 2018. 